CASE REPORT

\title{
Impacted Foreign Bodies in Primary and Permanent Teeth: A Report of Two Cases
}

\author{
Nivedita S Pande ${ }^{1}$, Shweta R Shirke ${ }^{2}$, HN Subhadra ${ }^{3}$, Amar N Katre $^{4}$
}

\begin{abstract} teeth as compared to primary teeth. the tooth was permanent and salvageable.

Keywords: Foreign body, Permanent teeth, Primary teeth.

Journal of Contemporary Dentistry (2020): 10.5005/jp-journals-10031-1279

\section{BACKGROUND}

Foreign bodies inside the teeth are either diagnosed clinically or accidentally on radiographs. They are commonly associated with consequences like infection, pain, swelling, dislodgment in the maxillary sinus or as discharging sinus, and/or abscess. ${ }^{1,2}$ Beads, 3,4 pencil leads, stapler pins, and toothpicks have been found in teeth. ${ }^{5}$ There are more reports of foreign bodies impacted in permanent teeth as compared to primary teeth. ${ }^{6}$
\end{abstract}

Aim and objective: Report unusual foreign bodies lodged in primary and permanent teeth.

Background: Children often insert foreign objects inside the teeth to alleviate tooth pain. Such instances are more often reported for permanent

Case descriptions: This case report presents two cases of foreign bodies lodged within the teeth. The first report is a case of a 7-year-old girl who reported pain and examination revealed a pin impacted tooth 54 (FDI nomenclature). The second case reports a case of a 9-year-old girl who presented with pain and on examination, a pencil lead and the nib of a fountain pen was found lodged in tooth 46 . In case 1, 54 was extracted considering the poor prognosis of the tooth. In case 2 , retrieval of the foreign object was undertaken followed by endodontic treatment because

Conclusion: In both cases, foreign bodies lodged in the pulp space were found on clinical examination and subsequently confirmed radiographically. The foreign bodies were retrieved successfully and teeth were treated.

\section{Case Descriptions}

CARE guidelines were used for this case report.

\section{Case 1}

A 7-year-old girl reported to the Department of Pediatric and Preventive Dentistry with pain in the upper right back tooth for 3-4 days. The patient had dull aching pain. There was no associated swelling. The medical history was noncontributory.

On clinical examination, 54 had a deep carious lesion with gross destruction of tooth structure. 55 had deep occlusal caries. Examination of 54 revealed a golden-colored object inside the tooth. The parents were unaware of the child inserting any foreign object inside the tooth. The second quadrant had a root piece of 64 and deep occlusal caries with 65 .

Intraoral periapical (IOPA) radiograph revealed a radio-opaque flat-ended nail-like object in the pulp chamber extending into furcation of the 54 and encroaching the developing crown of 14. 55 showed caries involving enamel and dentin (Fig. 1). Intraoral periapical with 64 revealed a root piece thereby confirming the clinical picture. 65 showed caries involving enamel and dentin.

Prognosis of the 54 was poor and hence, the tooth was indicated for extraction. The flat endpin was first located after clearing the debris using a three-way syringe. The pin was held with a tweezer and removed (Fig. 2). 54 was subsequently extracted under local

\footnotetext{
${ }^{1-4}$ Department of Pediatric and Preventive Dentistry, YMT Dental College and Hospital, Kharghar, Mumbai, Maharashtra, India

Corresponding Author: Nivedita S Pande, Department of Pediatric and Preventive Dentistry, YMT Dental College and Hospital, Kharghar, Mumbai, Maharashtra, India, Phone: +91 9552553496, e-mail: pande. nivedita@gmail.com

How to cite this article: Pande NS, Shirke SR, Subhadra HN, et al. Impacted Foreign Bodies in Primary and Permanent Teeth: A Report of Two Cases. J Contemp Dent 2020;10(1):34-36.

Source of support: Nil

Conflict of interest: None
}

anesthesia (2\% lignocaine with 1:80,000 adrenaline). The socket was irrigated with $5 \% \mathrm{w} / \mathrm{v}$ povidone iodine mixed with normal saline and inspected for any remnants. 64 was extracted a week after

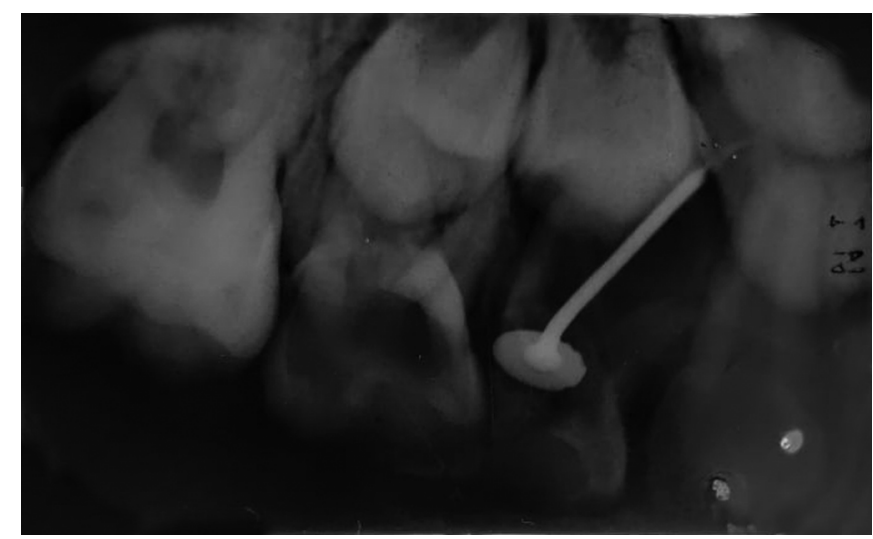

Fig. 1: IOPA of 54 showing the foreign body (pin) lodged in the pulp chamber and encroaching upon the developing 14 


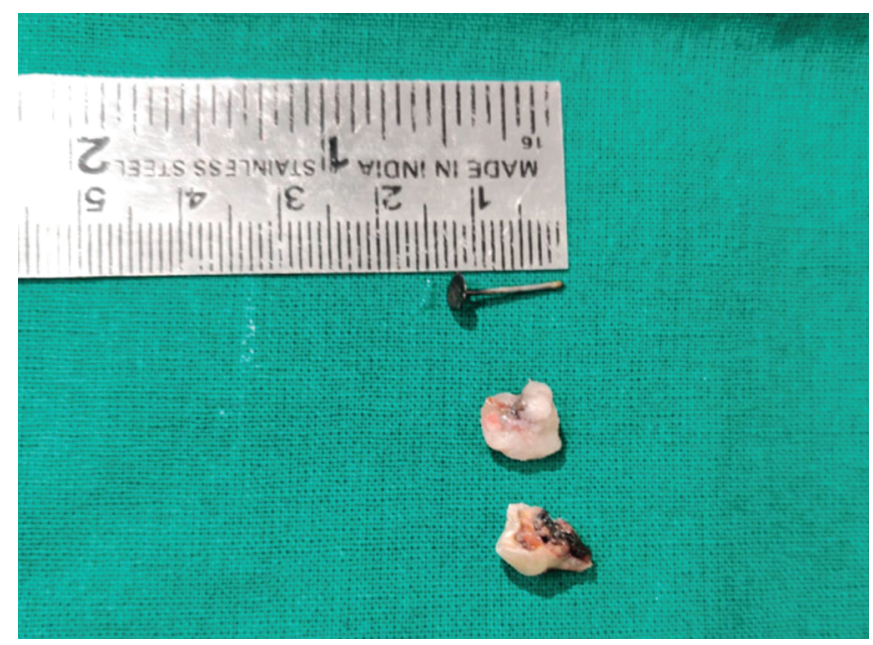

Fig. 2: $14 \mathrm{~mm}$ pin retrieved and 54 extracted

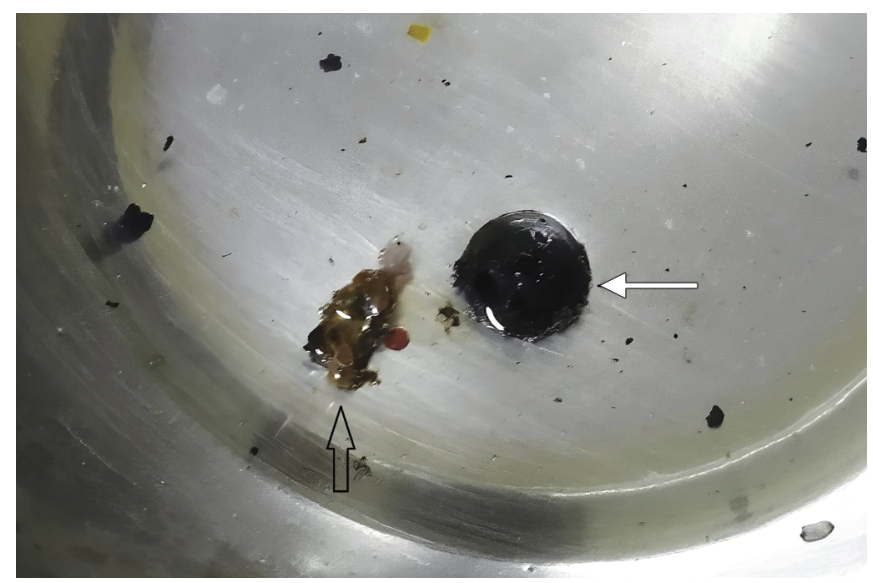

Fig. 4: Nib (black arrow) and pencil lead (white arrow) retrieved

extraction of 54.55 was restored with a stainless steel crown (Kidz Crown ${ }^{\mathrm{TM}}$, Kids Crowns, Korea) restoration and 65 with a reinforced GIC restoration (GC Fuji 9 Gold label $^{\mathrm{TM}}$, GC Inc, Japan).

Crown-band and loop space maintainer was given for 54 and a band and loop space maintainer was given for 64 . There were no complications following extraction or after the placement of the space maintainers. The patient did not report irritation, pain, or discomfort with the space maintainers on the re-call visits.

\section{Case 2}

A 9-year-old girl reported pain in the lower right back tooth for 2 weeks. There was no swelling. The patient had a dull aching pain. The medical history was non-contributory.

On oral examination, it was found that 46 had a large open carious lesion and a dark black-colored object was lodged in the pulp chamber. A foul, putrefied odor indicated necrosis. The parents were unaware of the child inserting any foreign object in the tooth. Intraoral periapical radiograph of 46 revealed a radiopacity resembling a wire within the pulp chamber. The root apices of 46 were closed but the mesial and distal roots had an ill-defined periapical radiolucency which approximately measured $2 \times 2 \mathrm{~mm}$ indicative of periapical abscess (Fig. 3). On interrogation, the patient revealed that she had placed a nib of a fountain pen and a pencil

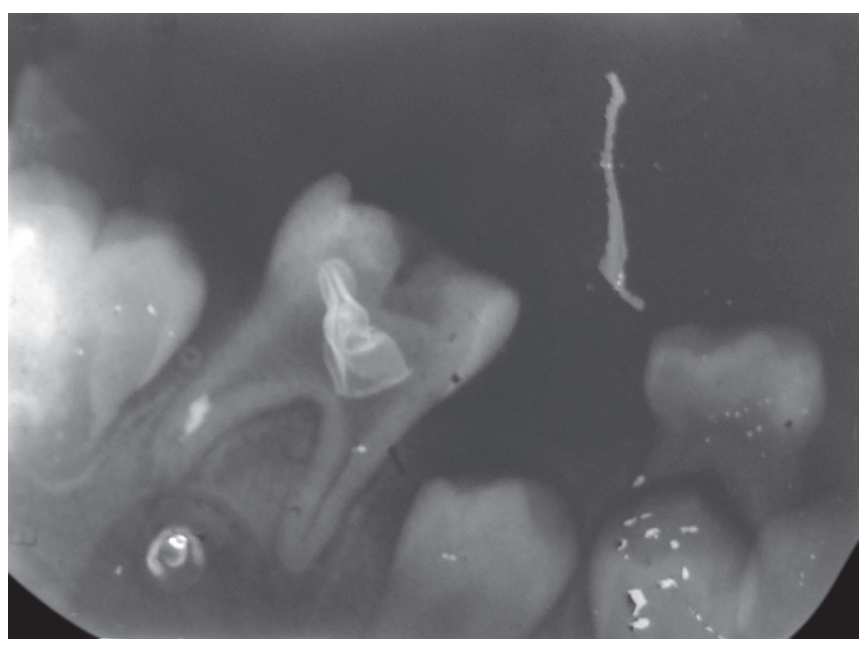

Fig. 3: IOPA of 46 showing the foreign body (nib) lodged in the pulp chamber and periapical radiolucency around the mesial and distal roots

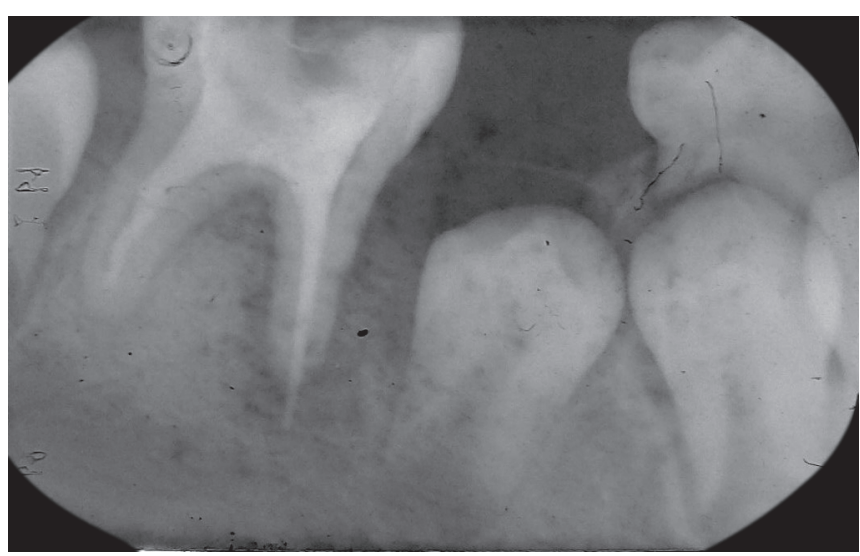

Fig. 5: IOPA postobturation with 46 and periapical radiolucency reduced with mesial root and no longer present with distal root

lead in the tooth to alleviate pain. However, she requested not to reveal this to her parents. The lead of the pencil was removed using a spoon excavator (Fig. 4). The nib of the fountain pen was retrieved using a tweezer. The access to the pulp chamber was open. Access was further refined for instrumentation. Working length determination and biomechanical preparation were done and completed on the same visit till the F3 hand Protaper (Dentsply Protaper Universal. Dentsply ${ }^{\mathrm{TM}}$, Switzerland). The access cavity was sealed (MD Temp. Meta Biomed ${ }^{\mathrm{TM}}{ }$, Korea). The patient was recalled after 4 days but a discharge from the canals was observed. The canals were irrigated with copious amounts of normal saline and $5.25 \%$ sodium hypochlorite. A calcium hydroxide intracanal medicament (RC Cal I. Prime Dental Products Pvt Ltd ${ }^{\mathrm{TM}}$, India) was placed in 46 and the access cavity was again sealed. The patient was recalled after one week and the canals were found to be dry. 46 Exhibited no tenderness on percussion; hence, gutta-percha obturation was done followed by post obturation restoration (POR) of access cavity with RMGIC (GC Fuji type II LC ${ }^{\mathrm{TM}}$. GC, Japan) (Fig. 5). The obturation in the mesial canals was slightly overextended but the patient remained asymptomatic. A week later, 46 was restored with a stainless steel crown (3M ESPE ${ }^{\text {TM }}$ Stainless Steel Permanent Molar crowns, USA). The patient is being followed up regularly and is asymptomatic. 


\section{Discussion}

The prognosis associated with 54 was poor. Additionally, the foreign body appeared to encroach the developing 14, hence extraction was carried out. The patient was in early mixed dentition, the permanent incisors had not erupted, hence a band and loop space maintainer was placed following extraction. ${ }^{7}$

The prognosis with 46 was good; hence, endodontic treatment was undertaken. Past literature shows such teeth have been treated endodontically. ${ }^{8,9}$ A semipermanent restoration like the stainless steel crown is indicated as an interim restoration after endodontic treatment until the occlusion is established. ${ }^{7}$

Various methods have been tried for the removal of the foreign body which includes ultrasonic instruments, ${ }^{10}$ the Masserann kit, ${ }^{11}$ and modified Castroviejo needle holders. ${ }^{12}$ In the present cases, the foreign bodies were located in the pulp chamber; hence, they could be easily retrieved using tweezers.

Foreign objects are seen lodged within large cavities to relieve pain. ${ }^{13}$ In pediatric dentistry, however, foreign objects are an accidental finding on routine radiographs. Parents often are unaware of the children inserting foreign objects inside the tooth. Children inherently have the fear of getting reprimanded in return. ${ }^{14}$ Younger children have the tendency usually to swallow or insert foreign objects in the mouth as a result of their pursuit to explore new things. ${ }^{2}$ This also encompasses an umbrella term "Self-embedding behavior" (SEB) ${ }^{15}$ which comprises the individual inserting inanimate objects in soft tissues, either under the skin or in muscles. However, both the cases do not reflect SEB.

Prompt and cautious management in treating foreign is important because they act as a source of infection. Actinomycosis has been reported with the placement of a piece of jewelry in the tooth. ${ }^{16}$ There are reports of maxillary sinusitis of dental origin due to penetration of a foreign body through the canal of the maxillary central incisor. ${ }^{17}$

Early management of dental problems will prevent the pain and discomfort associated with pulpally involved teeth, thereby preventing the children from using foreign objects to alleviate pain. Making the patient wait with the draining tooth for an hour or more followed by sealing the access cavity is also known to help in preventing impaction of other foreign bodies. ${ }^{18}$

\section{Conclusion}

Foreign bodies lodged in the pulp chamber were found clinically and confirmed radiographically in both our cases. Foreign bodies were successfully removed. Eventually, extraction was carried out followed by placement of space maintainers in the first case; and endodontic treatment followed by stainless steel crown restoration in the other.

\section{Clinical Significance}

Foreign bodies lodged inside a tooth can result in serious consequences like pain, swelling, sepsis, and possible damage to the underlying tooth bud. Early management of dental problems prevents pain and discomfort associated with pulpally involved teeth, thereby preventing children from inserting foreign objects into the teeth to alleviate pain.

\section{References}

1. Nerst H. Foreign body in the root canal. Quintessence Int Berl 1972;3:33-34.

2. Mahesh $\mathrm{R}$, Waseem $\mathrm{H}$. Unusual behavior in children-foreign object in tooth: a report of two cases. Ethiop J Health Sci 2014;24(4):369-373. DOI: 10.4314/ejhs.v24i4.14.

3. Grossman JL, Heaton JF. Endodontic case reports. Dent Clin North Am 1974;118(2):509-527.

4. Subba RVV, Mehta DS. Beads. Oral Surg Oral Med Oral Pathol 1990;69(6):769-770. DOI: 10.1016/0030-4220(90)90366-Z.

5. Aduri R, Reddy RE, Kiran K. Foreign objects in teeth: retrieval and management. J Indian Soc Pedod Prevent Dent 2009;27(3):179-183. DOI: 10.4103/0970-4388.57100.

6. Holla G, Baliga S, Yeluri R, et al. Unusual objects in the root canal of deciduous teeth: a report of two cases. Contemp Clin Dent 2010;1(4):246-248. DOI: 10.4103/0976-237X.76393.

7. Dean JA, Avery DR, McDonald RE. Dentistry for the child and adolescent. Boston: Mosby; 2011. p. 563.

8. Nadkarni UM, Munshi A, Damle SG, et al. Retrieval of a foreign object from the palatal root canal of a permanent maxillary first molar: a case report. Quintessence Int 2002;33(8):609-612.

9. Keerthi Chand SJ, Varughese JM, Nair MG, et al. Endodontic management of an unusual foreign body in a maxillary central incisor. J Conserv Dent 2013;16(5):474-476. DOI: 10.4103/0972-0707. 117496.

10. Meidinger DL, Kabes BJ. Foreign object removal utilizing the caviendo ultrasonic instrument. J Endodont 1985;11(7):301-304. DOI: 10.1016/S0099-2399(85)80161-8.

11. Williams VD, Bjorndal AM. The Masserann technique for the removal of fractured posts in endodontically treated teeth. J Prosthet Dent 1983;49(1):46-48. DOI: 10.1016/0022-3913(83)90236-6.

12. Fros UGH, Berg JO. A method for the removal of broken endodontic instruments from root canals. J Endodont 1983;9(4):156-159. DOI: 10.1016/S0099-2399(83)80038-7.

13. Kanumuri PK, Gantha SN, Animireddy D, et al. Unusual foreign body in primary tooth. BMJ Case Rep 2016;2016:bcr2016216326. DOI: 10.1136/ bcr-2016-216326.

14. LehI G. Foreign body in a deciduous incisor: a radiological revelation. J Indian Soc Pedod Prev Dent 2010;28(1):45-46. DOI: 10.4103/09704388.60475 .

15. Bennett $\mathrm{GH}$, Shiels WE, Young AS, et al. Self-embedding behavior: a new primary care challenge. Pediatrics 2011;127(6):1386-1391. DOI: 10.1542/peds.2010-2877.

16. Goldstein BH, Scuibba JJ, Laskin DM. Actinomycosis of the maxilla: a review of literature and report of a case. J Oral Surg 1972;30(5):362366.

17. Costa F, Robiony $M$, Toro C, et al. Endoscopically assisted procedure for removal of a foreign body from the maxillary sinus and contemporary endodontic surgical treatment of the tooth. Head Face Med 2006;2(1):37. DOI: 10.1186/1746-160X-2-37.

18. Weine FS. Endodontic therapy. 6th ed., St. Louis, MO: Mosby; 2003. pp. 104-163. 